\title{
FULLY REMOTE CONTROLLED TELEMETRY TRACKING ANTENNA SYSTEM
}

\author{
E. Payne \\ Senior Applications Engineer \\ Scientific-Atlanta, Inc. \\ Atlanta, GA 30345
}

Franz Haider

Manager Flight Test Ground Station

MBB Deutsche Aerospace

\begin{abstract}
This paper describes a high performance telemetry receiving antenna tracking system which utilizes unique software to allow full remote control of the tracking antenna, two telemetry receivers, and a diversity combiner.

Features include a modular pedestal design, electronically scanned tracking feed (ESCAN), mouse-driven software which uses full screen representation of selected components, and a joystick linked through serial interface to the control computer to allow slewing of the antenna axes.
\end{abstract}

This state-of-the-art system allows operation from the front panel of the controlled devices and over extended distance via fiber-optic buss extenders.

\section{INTRODUCTION}

MBB Deutsche Aerospace receives, demodulates and reports aircraft flight test data. The nature of these flights require a dynamic broad frequency range tracking antenna meeting high operational and performance specifications. The location of the antenna test tower in relation to the main control center required a method of fully autonomous remote control.

\section{THE REQUIREMENT}

To meet current and future needs, the tracking system had to be capable of tracking and receiving data in a broad frequency range (1430 to $2600 \mathrm{MHZ}$ ). The ability to track targets which induce modulation (helicopters, rolling airframes, etc.) was required along with good low elevation and multipath performance. Experience also dictated that the method of remote control should not require vastly different operating technique than needed to operate the Servo Control Unit (SCU), telemetry receivers, or diversity combiner from their respective front panels. 


\section{THE SYSTEM}

The tracking system (see Figure 1-1) designed by Scientific-Atlanta utilizes an ESCAN feed mounted prime focus in an 8 -foot reflector. Table I gives the primary measured system performance data. A modular pedestal featuring pulse width modulated power amplifiers coupled with a microprocessor-based servo control unit were also utilized. Figure 1-2 shows the block diagram configuration of the Antenna system. A personal computer with custom mouse-driven software, Utilizing IEEE-488 remote interface was used to fulfill remote operation requirements (see Figure 1-3). During low level short distance flight situations an S-band dipole antenna is used to receive flight test data. Aircraft position data included with the data stream is processed in a mainframe host computer and used to reposition the main antenna via fiber-optic RS-232 link with the servo controller.

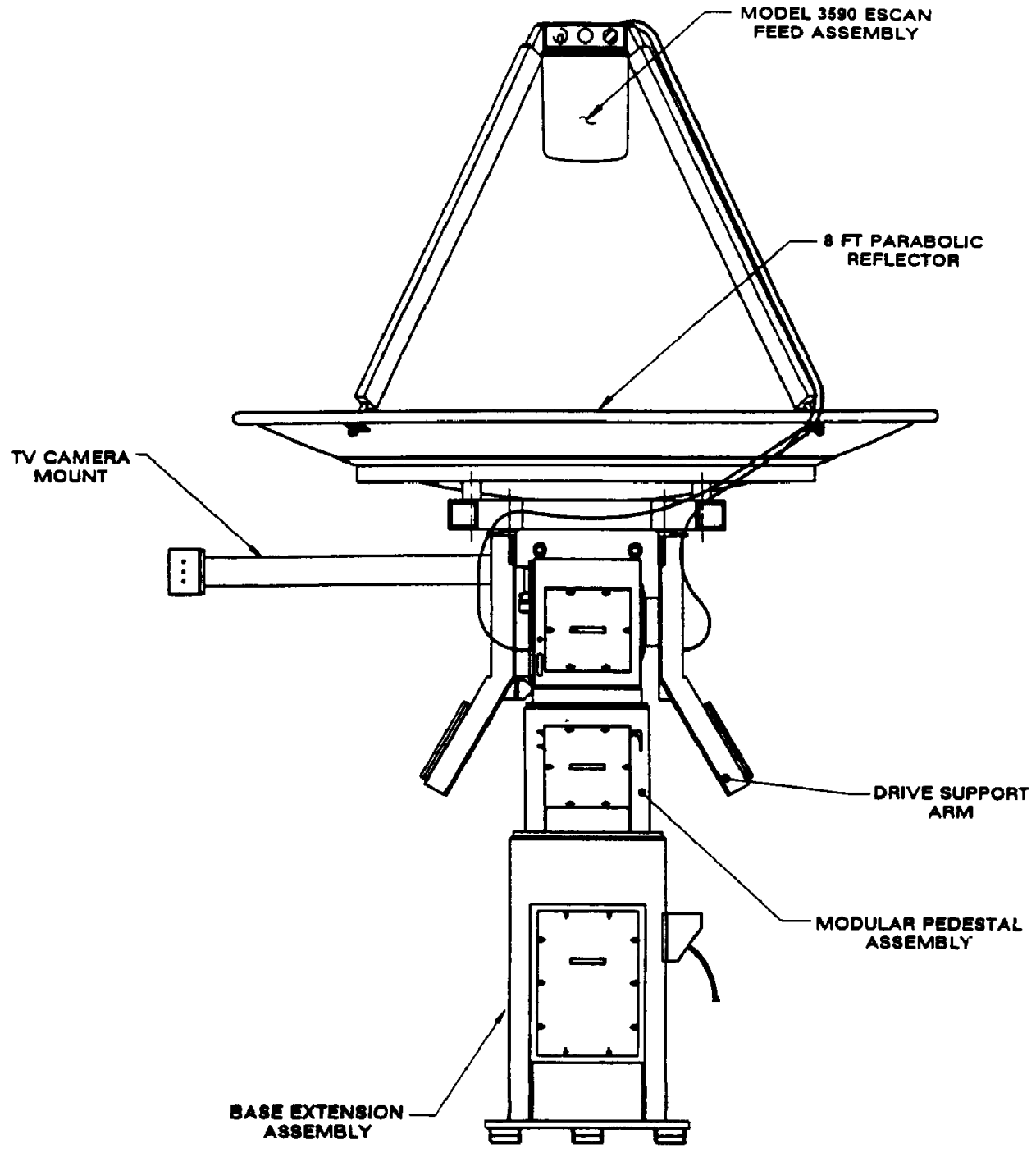

02713

Figure 1-1. MBB Antenna Assembly 


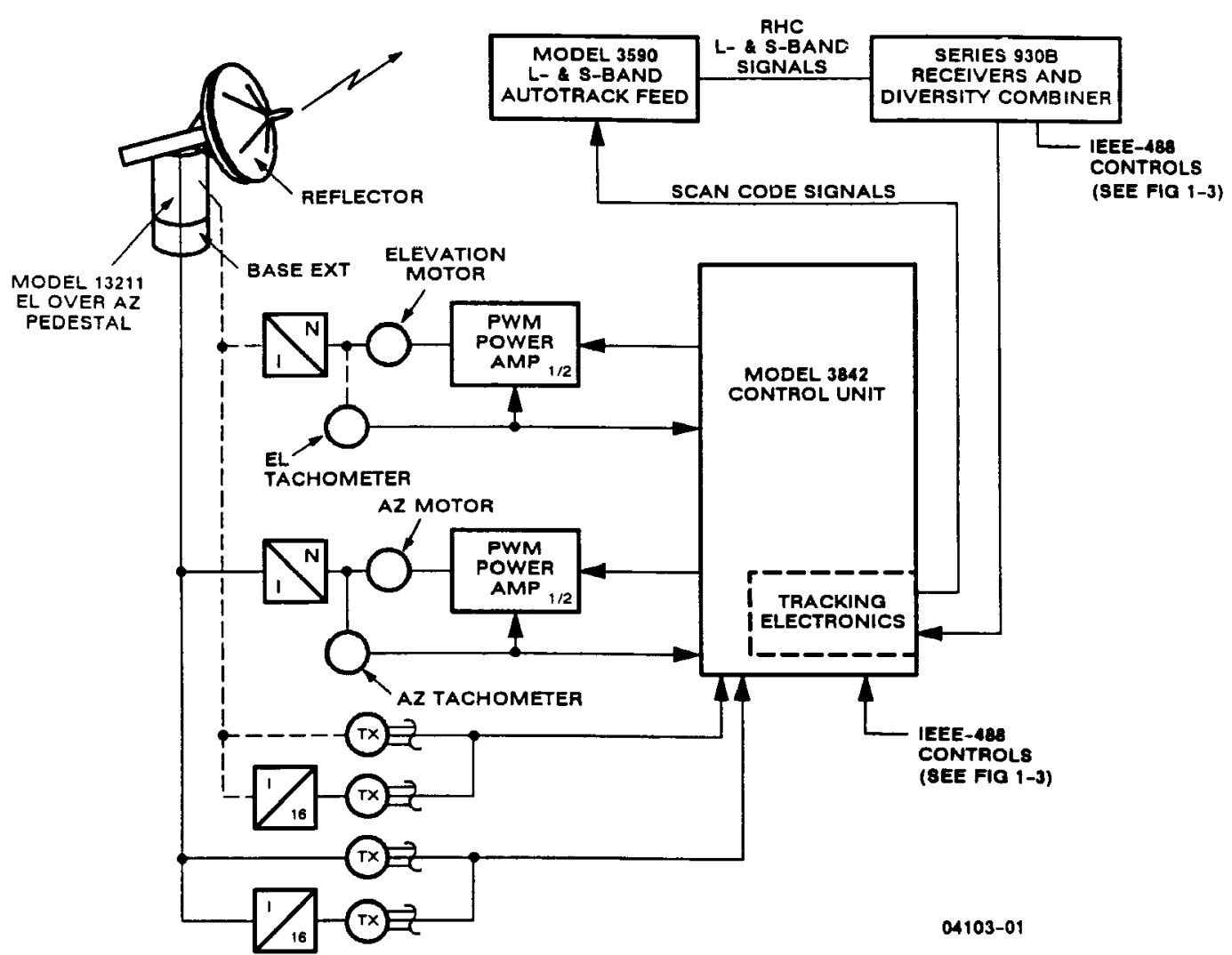

Figure 1-2. Antenna System Block Diagram

Table I

System Performance Data

\begin{tabular}{|c|c|}
\hline Characteristic & Specification \\
\hline \multicolumn{2}{|c|}{ Measured RF Performance } \\
\hline Frequency & 1435 to $2600 \mathrm{MHZ}$ \\
\hline Polarization & RHC \\
\hline $3 \mathrm{~dB}$ Beamwidth & $\begin{array}{l}5.2 \text { degrees at } 1435 \mathrm{MHZ} \\
3.2 \text { degrees at } 2600 \mathrm{MHZ}\end{array}$ \\
\hline Gain & $\begin{array}{l}27.3 \mathrm{dBi} \text { at } 1435 \mathrm{MHZ} \\
32.0 \mathrm{dBi} \text { at } 2600 \mathrm{MHZ}\end{array}$ \\
\hline Side lobe (relative to peak of main beam) & $\begin{array}{l}\text { 17.7 dB Max } \\
20.5 \text { dB Typical }\end{array}$ \\
\hline Axial Ratio & $1.5 \mathrm{~dB}$ Max \\
\hline VSWR & 1.5:1 Max \\
\hline
\end{tabular}




\begin{tabular}{|c|c|}
\hline Characteristic & Specification \\
\hline \multicolumn{2}{|c|}{ Mechanical } \\
\hline Primary Power & $120 \mathrm{~V} \mathrm{ac}, 1$ phase for each \\
\hline Drive Type & Brushless dc servomotor \\
\hline Power Gearing Backlash & $0.05 \mathrm{deg}$ \\
\hline Velocity & $30 \mathrm{deg} / \mathrm{sec}$ \\
\hline Acceleration & $30 \mathrm{deg} / \mathrm{sec} 2$ \\
\hline Gear Ratio & $1,466: 1$ \\
\hline Compliance & $5 \times 10^{-6} \mathrm{rad} / \mathrm{ft}-\mathrm{lb}$ \\
\hline $\begin{array}{l}\text { Azimuth Bearing Overturning Moment } \\
\text { Capacity }\end{array}$ & $4,000 \mathrm{ft}-\mathrm{lb}$ \\
\hline System Weight & $900 \mathrm{lbs}$ \\
\hline Orthogonality Tolerance & $0.03 \mathrm{deg}$ Max \\
\hline Reflected Inertia & $25 \mathrm{sl}-\mathrm{ft}^{2}$ \\
\hline Delivered Torque & $500 \mathrm{ft}-1 \mathrm{~b}$ \\
\hline Stow Angle & $\begin{array}{l}\text { Azimuth } 0^{\circ} \\
\text { Elevation } 90^{\circ} \\
\text { Alternate positions in } 90^{\circ} \text { increments }\end{array}$ \\
\hline Overall System Height & 156 in \\
\hline \multicolumn{2}{|c|}{ Environmental } \\
\hline Temperature & $-20^{\circ} \mathrm{C}$ to $+55^{\circ} \mathrm{C}$ \\
\hline Relative Humidity & $100 \%$ including condensation \\
\hline $\begin{array}{l}\text { Ice Load } \\
\text { Operating } \\
\text { Nonoperating }\end{array}$ & $\begin{array}{l}1 / 8 \text { in } \\
1 / 4 \text { in }\end{array}$ \\
\hline $\begin{array}{l}\text { Wind } \\
\text { Operating } \\
\text { Survival }\end{array}$ & $\begin{array}{l}35 \mathrm{mph} \\
90 \mathrm{mph} \text { (stowed) }\end{array}$ \\
\hline
\end{tabular}




\begin{tabular}{||l|l||}
\hline \multicolumn{1}{|c|}{ Characteristic } & \multicolumn{1}{|c|}{ Specification } \\
\hline \begin{tabular}{||l||} 
Altitude \\
Operating \\
Nonoperating
\end{tabular} & $\begin{array}{l}0 \text { to } 10,000 \mathrm{ft} \\
0 \text { to } 50,000 \mathrm{ft}\end{array}$ \\
\hline Salt Atmosphere & Coastal regions \\
\hline Sand and Dust & Desert regions \\
\hline Insects and Fungi & Tropical regions (MIL-STD-454/4) \\
\hline $\begin{array}{l}\text { Vibration } \\
\text { Pedestal }\end{array}$ & $\begin{array}{l}\text { MIL-STD-167 (shipboard) shock typically, } \\
30 \mathrm{G}, \text { saw tooth impulse } \\
\text { Formal highway (unimproved roads) or air } \\
\text { shipment }\end{array}$ \\
\hline
\end{tabular}

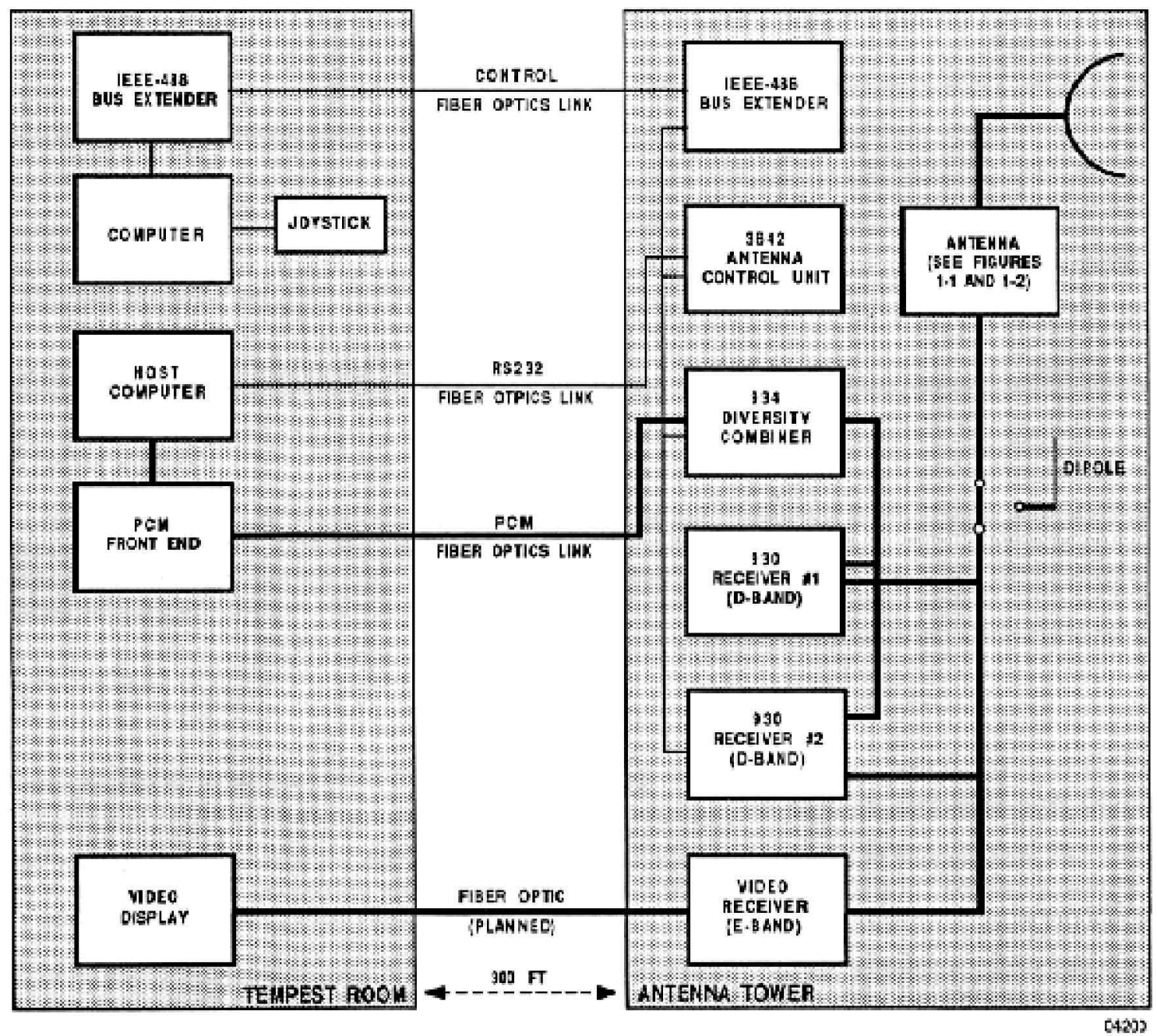

Figure 1-3. Control Layout of the MBB Antenna/Receiving System 


\section{$\operatorname{ESCAN}^{1}$}

The ESCAN feed, which has been published in two previous papers presented to the ITC, is a prime focus, electronically scanned tracking feed. This feed provides operation from $1400 \mathrm{MHZ}$ through $2600 \mathrm{MHZ}$. Target induced modulation is eliminated by the choice of high fixed, swept, or pseudorandom scan rates. Excellent low side-lobe performance (see Table I) coupled with digital autotrack demodulation in the servo control unit provide excellent low elevation angle/high multipath environment tracking capability.

\section{MODULAR PEDESTAL}

The Model 13211 Modular Pedestal selected for this application places all servo drive components on a single diaphragm which is identical for azimuth and elevation.

The turntables are supported by precision four point contact ball bearings which are retained in stainless steel support rings to better control differential thermal expansion and thereby reduce friction and bearing stress. The main drive gear is attached directly to the inside race of the bearing to provide excellent strength and rigidity to the drive train.

A combination brake, tachometer, and high torque servo motor are coupled to a compact spur gear reducer to drive each aids. These components are provided as one line-replaceable unit to speed future service requirements. Final drive to the bearing gear is through a spring biased anti-backlash pinion. The final drive cavity in the module contains a foam volume reducer to ensure that lubrication remains in the gear contact area further enhancing reliability.

A rotary joint and slipring were provided to allow continuous azimuth rotation.

\section{COMPUTER CONTROL SYSTEM}

The tracking antenna is located on a tower with a control room directly underneath housing the Scientific-Atlanta Model 3842 Controller, two Model 930B Telemetry Receivers, and a Model 934 Diversity Combiner. Control of these devices was required from a tempest control facility locted 300 feet from the antenna tower. The ability to slew the pedestal with a joystick from both locations was also furnished.

A personal computer using IEEE-488 addressable format along with fiber-optic line extenders was selected (see Figure 1-3).

${ }^{1} \mathrm{ESCAN}$ is a patented process of Scientific-Atlanta, Inc. 
Mouse-driven software was written using the familiar icon format to select each device (see Figure 1-4).

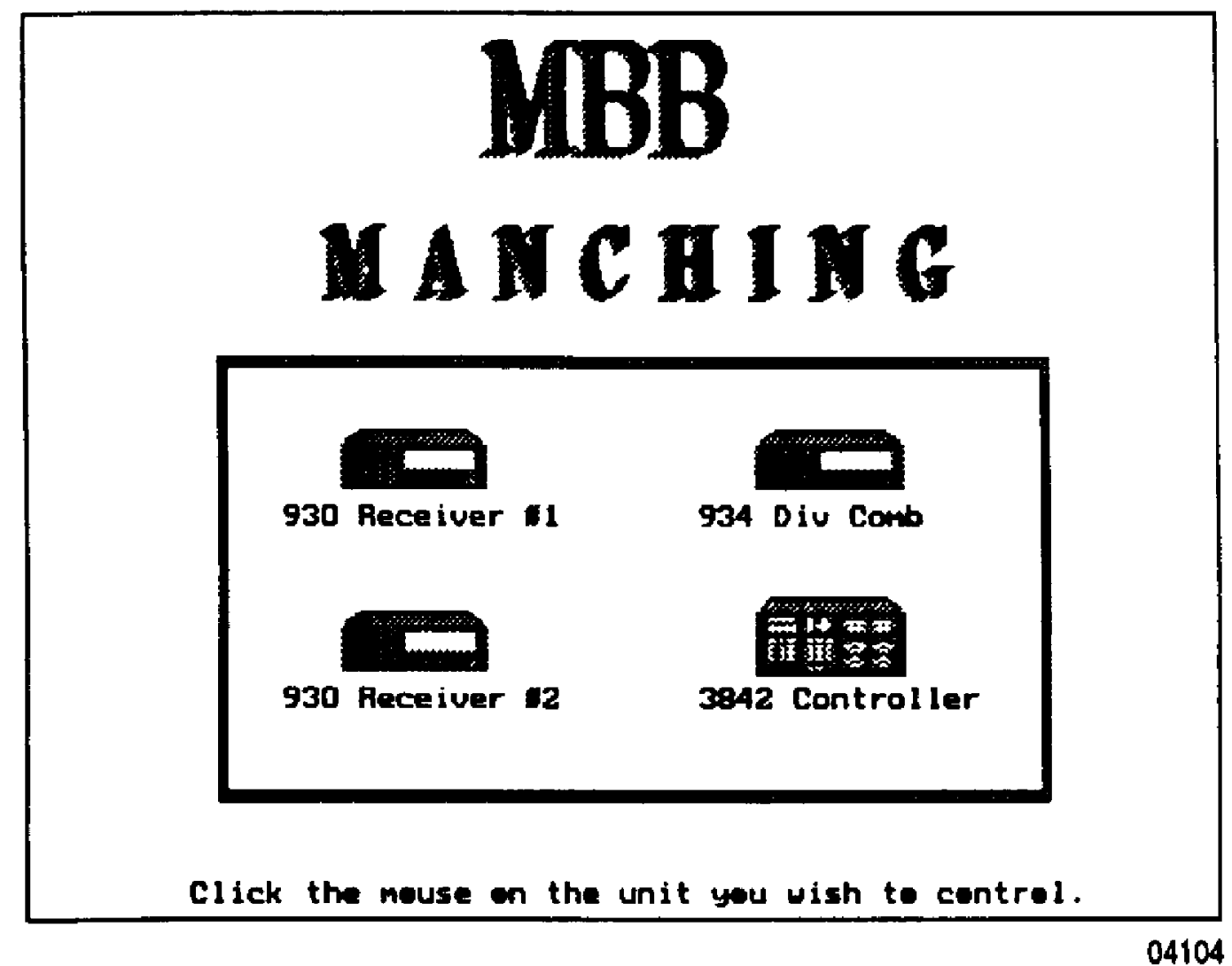

Figure 1-4. Control Entry Screen

Following selection, a full-screen representation of the device is then presented. See Figures 1-5 through 1-8. All operations are then very similar to front-panel operation. Mode changes are accomplished by clicking the mouse over the chosen mode key, the key will change color to yellow indicating the command is in process. The key will then become green indicating that the mode is active.

A data entry screen was also provided on the Servo Control Unit (Figure 1-6) which allows the operator to view and change control parameters which are internal to the controller and not displayed on the front panel. Accessed from the controller screen, each parameter has a separate box on the display which shows the current value for that parameter (updated continuously) and which may be selected and changed. Normal background color for these parameters is gray; when a box is selected the background color will change to green and the key pad and entry field are activated.

An external joystick was supplied to allow rapid repositioning of the axes. Operating through a serial input port, the joystick allows axis speeds in proportion to stick deflection. 


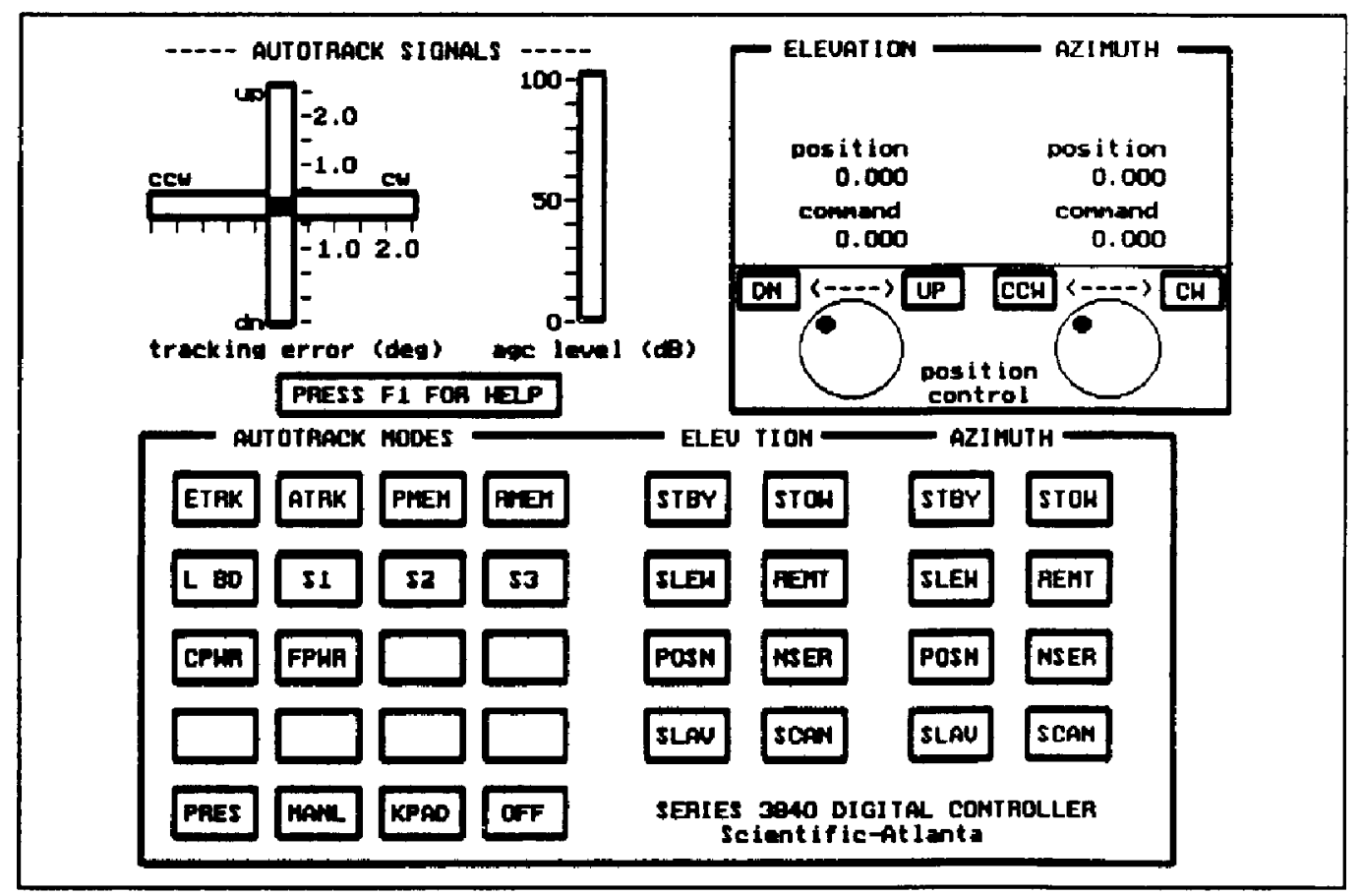

04105

Figure 1-5. Servo Controller Remote Screen

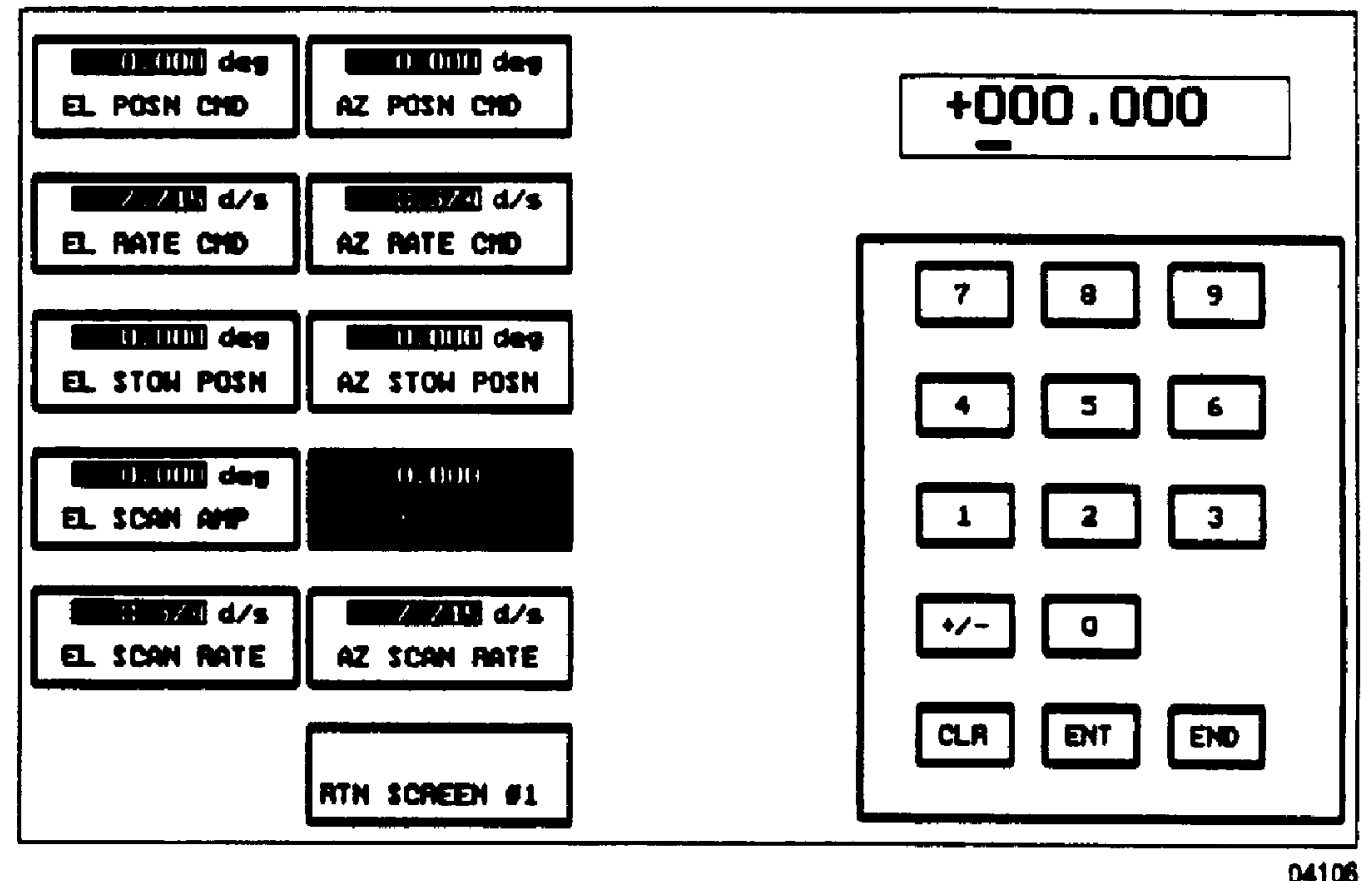

Figure 1-6. Data Entry Screen 


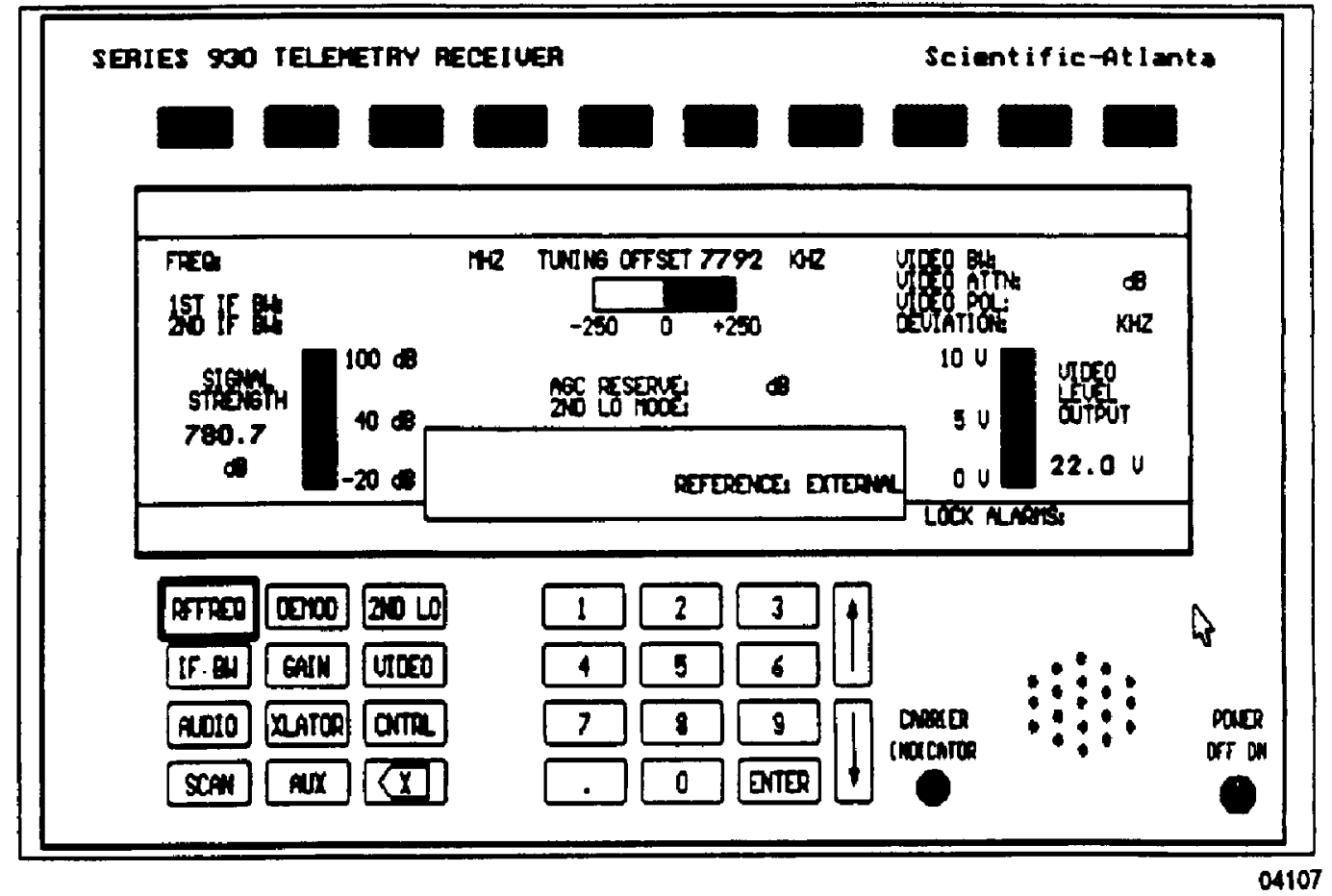

Figure 1-7. Telemetry Receiver Screen

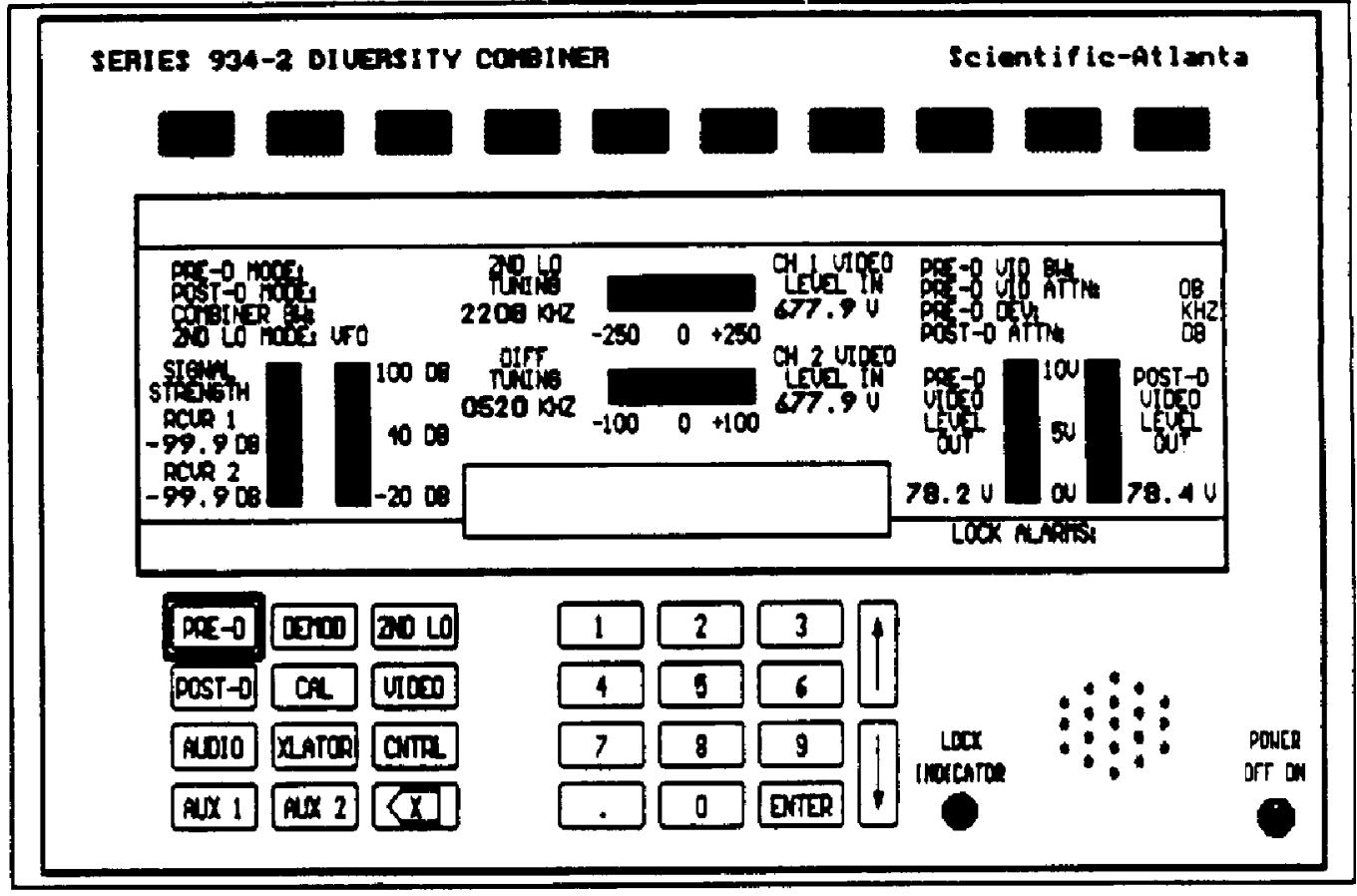

04108

Figure 1-8. Diver sity Combiner Screen 
Depressing a button on the joystick base reduced stick deflection rates by one half to allow more precise positioning.

The Series 930 Equipment uses a menu-driven logic access to set-up and tuning functions. This operation method was exactly matched on the computer screen where selection of a "hard key" or fixed function key provides additional parameters selectable from the "soft keys" located across the top of the panel. See Figures 1-6 and 1-7.

\section{SERIAL INTERFACE DATA OUTPUT}

To provide a constant output of device status, the computer will continuously output the status of all four devices being controlled via a serial interface to an existing mainframe computer. The data repeats itself continuously with each device identified with a unique prefix followed by data represented in HEX-ASCII format for all major device parameters.

\section{CONCLUSION}

This system represents a full function, high performance, telemetry tracking system which meets a broad range of performance requirements. During operation, the system has proven highly functional in a wide variety of flight regimes as well as during low elevation angle tracking situations. The ability to switch to a dipole antenna during close-in high speed situations while simultaneously updating the position of the tracking antenna to regain track as soon as possible insures constant test data.

The unique computer control system allows operators the ability to control all system parameters from a remote location using the same basic control logic found on the device front panel. 